\title{
Correction to: Reducing New Persistent Opioid Use After Surgery: a Review of Interventions
}

\author{
Stacey Burns ${ }^{1}\left[\right.$. $\cdot$ Richard Urman ${ }^{1,2} \cdot$ Rachel Pian $^{3} \cdot$ Oscar Jim Michael Coppes ${ }^{4}$ \\ Published online: 5 November 2021 \\ ๑) Springer Science+Business Media, LLC, part of Springer Nature 2021
}

Correction to: Current Pain and Headache Reports (2021) 25: 27
https://doi.org/10.1007/s11916-021-00943-6

The article "Reducing New Persistent Opioid Use After Surgery: A Review of Interventions," written by Stacey Burns, Richard Urman, Rachel Pian, and Oscar Jim Michael Coppes, was originally published online on the publisher's internet portal on March 24, 2021 with Open Access under a Creative Commons Attribution (CC BY) license 4.0.

With the authors' decision to cancel Open Access, the copyright of the article changed on October 14, 2021 to (C) Springer Science+Business Media, LLC, part of Springer Nature 2021 with all rights reserved.

Publisher's Note Springer Nature remains neutral with regard to jurisdictional claims in published maps and institutional affiliations.

The online version of the original article can be found at: https:// doi.org/10.1007/s11916-021-00943-6.

Stacey Burns

sburns0@bwh.harvard.edu

1 Department of Anesthesiology, Perioperative and Pain Medicine, Brigham and Women's Hospital, 75 Francis Street, Boston, MA 02115, USA

2 Center for Perioperative Research, Department of Anesthesiology, Perioperative and Pain Medicine, Brigham and Women's Hospital, Harvard Medical School, Boston, MA, USA

3 Department of Biology, Boston University, Boston, MA, USA

4 Department of Anesthesia and Critical Care, University of Chicago, Chicago, IL, USA 